\title{
Association Between Baseline Anti-cyclic Citrullinated Peptide Antibodies and 6-Month Clinical Response Following Abatacept or TNF Inhibitor Treatment: A Real-World Analysis of Biologic-Experienced Patients with RA
}

Leslie R. Harrold (1) · Joshua Bryson · Thomas Lehman · Joe Zhuo · Sheng Gao · Xue Han •

Amy Schrader $\cdot$ Sabrina Rebello $\cdot$ Dimitrios A. Pappas · Tanya Sommers $\cdot$ Joel M. Kremer

Received: January 28, 2021 / Accepted: April 19, 2021 / Published online: May 28, 2021

(C) The Author(s) 2021

\section{ABSTRACT}

Introduction: Anti-cyclic citrullinated peptide (anti-CCP) antibodies are associated with poor prognosis in patients with rheumatoid arthritis (RA). Previous data from randomized controlled trials and clinical practice have shown anti-CCPpositive (+) patients had a better response to treatment with abatacept or tumor necrosis factor inhibitor (TNFi) treatment than those who were anti-CCP negative. This study assessed the association between baseline anti-CCP2 [a surrogate for anti-citrullinated protein antibody (ACPA)] concentration and 6-month treatment responses to abatacept or TNFi in patients with RA.

Supplementary Information The online version contains supplementary material available at https:// doi.org/10.1007/s40744-021-00310-2.

Sabrina Rebello: CorEvitas employee at the time of the work that was conducted on this project.

L. R. Harrold $(\bowtie) \cdot$ A. Schrader · D. A. Pappas

T. Sommers

CorEvitas, LLC, 1440 Main Street, Suite 310,

Waltham, MA 02451, USA

e-mail: lharrold@corevitas.com

L. R. Harrold

University of Massachusetts Medical School, 55 Lake

Avenue North, Worcester, MA 01655, USA

J. Bryson - T. Lehman · J. Zhuo $\cdot$ S. Gao $\cdot$ X. Han Bristol Myers Squibb, 100 Nassau Park Blvd \#300, Princeton, NJ 08540, USA
Methods: This real-world analysis included biologic-experienced patients from CERTAIN (Comparative Effectiveness Registry to study Therapies for Arthritis and Inflammatory CoNditions) who initiated abatacept or TNFi, had prior biologic disease-modifying drug exposure and baseline anti-CCP2 concentration/ serostatus and serum samples (baseline and 6 months). Baseline demographics and disease characteristics were compared. Change from baseline at 6 months in Clinical Disease Activity Index (CDAI) score and patient-reported outcomes [PROs: pain, fatigue, patient global assessment (PtGA), modified Health Assessment Questionnaire (mHAQ) score], by baseline antiCCP2 quartile and binary cut-off ( $>10-250$ and $>250 \mathrm{U} / \mathrm{ml}$ ), were evaluated separately in the abatacept and TNFi groups using a linear regression model adjusted for age, sex, CDAI/ PROs, comorbidity index, and methotrexate use. Results: Included were 138 abatacept and 137 TNFi initiators who were anti-CCP2+. At

S. Rebello

Amyloidosis Research Consortium, 320 Nevada

Street, Suite 210, Newton, Massachusetts 02460, USA

\section{A. Pappas}

Department of Medicine, Columbia University, 630

West 168th Street, New York, NY, USA

J. M. Kremer

Albany Medical College and the Center for

Rheumatology, 47 New Scotland Ave, Albany, NY

12208, USA 
baseline, there were significant differences between anti-CCP2 quartiles and mean CDAI, swollen joint count 28, C-reactive protein (CRP), Disease Activity Score 28 (CRP), rheumatoid factor (RF), mHAQ and physician global assessment among abatacept initiators, and in mean RF, mHAQ, and PtGA among TNFi initiators. Among abatacept (but not TNFi) initiators, CDAI numerically improved $(p=0.208)$ and PROs significantly improved $(p<0.05)$ with increasing baseline anti-CCP2.

Conclusions: In patients treated with abatacept, not TNFi, higher anti-CCP2 concentrations at baseline were associated with numerically greater improvements in CDAI and significant improvements in PROs after 6 months.

Clinical Trial Number: NCT01625650.

\section{PLAIN LANGUAGE SUMMARY}

Rheumatoid arthritis (RA) is an autoimmune disease - a disease that causes the immune system to attack an individual's own body. A key feature of RA is the presence of proteins called autoantibodies in the blood. While antibodies help protect against external threats such as viruses, autoantibodies mistakenly target an individual's own tissues and organs. One type of autoantibody often found in patients with RA is called anti-cyclic citrullinated peptide (anti-CCP). Studies have shown that patients with RA with anti-CCP antibodies may experience worse physical symptoms, function, disease activity, and outcomes than patients with RA without anti-CCP antibodies. Clinical trials suggest that some drugs may be more effective than others at managing symptoms of RA in patients who have anti-CCP in their blood. It is important to study this further to give doctors a sense of how patients respond to drug therapy in the 'real world', without clinical trial constraints. This study examined real-world patient data to see whether the presence of anti-CCP in patients' blood impacted how their RA symptoms responded to treatment with two different drugs: abatacept or a tumor necrosis factor inhibitor (TNFi). This study found that patients with higher levels of anti-CCP at the start of the study, compared with patients with lower levels of anti-CCP, experienced less disease activity and greater improvement in physical function after 6 months of treatment with abatacept. The study found no relationship between anti-CCP and treatment response after 6 months of treatment with a TNFi.

Keywords: Abatacept; Patient-reported outcome measures; Rheumatoid arthritis; Tumor necrosis factor inhibitors

\section{Key Summary Points}

\section{Why carry out this study?}

Anti-cyclic citrullinated peptide (antiCCP) antibodies are highly specific serological biomarkers associated with poor clinical prognosis in patients with rheumatoid arthritis (RA), including higher disease activity, more rapid radiographic disease progression, and greater impairment of physical function.

An important consideration for physicians treating patients with RA is that treatment responses can vary depending on the clinical characteristics of the patients; therefore, an individualized treatment approach may be needed.

Previous data from clinical trials and clinical practice suggest that bDMARDs with different mechanisms of action may result in differential treatment responses, depending on a patient's anti-CCP serostatus.

\section{What was learned from the study?}

In this post hoc analysis of the prospective CERTAIN cohort study, biologicexperienced patients with RA and higher (versus lower) anti-CCP2 concentrations at baseline had numerically, but not statistically, greater improvements in CDAI score and significantly greater improvements in patient-reported outcomes after 6 months of treatment with abatacept.

No association between baseline antiCCP2 concentration and treatment response was observed in patients treated with a tumor necrosis factor inhibitor. 


\section{DIGITAL FEATURES}

This article is published with digital features, including a summary slide and plain language summary to facilitate understanding of the article. To view digital features for this article go to $\quad$ https://doi.org/10.6084/m9.figshare. 14438786 .

\section{INTRODUCTION}

Rheumatoid arthritis (RA) is characterized by the production of autoantibodies, including rheumatoid factor (RF) and anti-citrullinated protein antibodies (ACPAs) [1, 2]. Anti-cyclic citrullinated peptide (anti-CCP, a surrogate for ACPA), is a highly specific serological biomarker that physicians can use in the clinic to guide therapy; anti-CCP positivity is associated with poor prognosis in patients with RA [3-5]. Patients with RA who are ACPA/anti-CCP positive $(+)$, compared with those who are ACPA/ anti-CCP negative (-), have been shown to have worse clinical outcomes, including higher disease activity, more rapid radiographic disease progression, greater impairment of physical function, and increased mortality [3-7].

Current European League Against Rheumatism (EULAR) and American College of Rheumatology (ACR) treatment guidelines recommend a treat-to-target approach in order to achieve and maintain a state of sustained remission or low disease activity [4, 8]. However, there are few data available to guide sequencing of biologic disease-modifying antirheumatic drugs (bDMARDs) in the event of treatment failure with first-line therapy with conventional synthetic DMARDs, such as methotrexate (MTX). An important consideration for physicians treating patients with RA is that treatment responses can vary depending on the clinical characteristics of the patients. Thus, an individualized treatment approach may be needed $[9,10]$. Specific serological biomarkers, such as ACPAs, that are indicative of a poor prognosis may be useful as part of such an approach. ACPAs are measured using anti-CCP antibody assays; the second and third generations of anti-CCP assays (CCP2 and CCP3) have been shown to be good measures of CCP $[11,12]$.

Clinical trial data suggest that bDMARDs with different mechanisms of action may result in differential treatment responses depending on a patient's ACPA serostatus [13-15]. A post hoc analysis of the AMPLE (Abatacept versus adaliMumab comParison in bioLogic-naivE RA subjects with background MTX) trial demonstrated that patients treated with abatacept or a tumor necrosis factor inhibitor (TNFi; adalimumab) who were anti-CCP2+, versus those who were anti-CCP2-, had a better response to treatment at 12 months [13]. Additionally, patients with RA who had higher baseline antiCCP2 concentrations showed a better response to treatment with abatacept than those with lower concentrations, an association that was not observed with adalimumab treatment [13]. Real-world data from the large, US-based, Corrona RA Registry have demonstrated similar findings. An analysis from the Corrona RA Registry, which included patients with RA initiating treatment with abatacept $(n=566)$ or a TNFi $(n=1715)$, showed that anti-CCP status was associated with a differential treatment response to abatacept but not to TNFi [14].

CERTAIN (Comparative Effectiveness Registry to study Therapies for Arthritis and Inflammatory CoNditions) was a prospective cohort study of adult patients with RA (ClinicalTrials.gov: NCT01625650) [16]. Patients included in CERTAIN were recruited from the Corrona RA Registry network and had at least moderate disease activity [Clinical Disease Activity Index (CDAI) score $\geq 10$ ], had either started therapy with or switched to a TNFi or non-TNFi bDMARD and were followed for 12 months or until they switched/discontinued the bDMARD $[16,17]$. Prior analyses of patients who were anti-CCP+ (bDMARD-naive or -experienced) from the Corrona RA Registry network have shown that patients had similar outcomes at 6 months when treated with abatacept versus a TNFi: there was no significant difference in response [17]. However, a subgroup analysis found that there was a significant difference in reduction of disease activity at 6 months in favor of abatacept, compared with TNFi treatment, among patients with anti- 
CCP+RA who were biologic-experienced [17]. Therefore, the purpose of the present study was to use data from CERTAIN to evaluate the effects of different baseline anti-CCP2 concentrations on the change in clinical and patientreported outcome (PRO) response from baseline to 6-month follow-up among patients separately initiating abatacept or a TNFi.

\section{METHODS}

\section{Study Sample}

\section{Overall CERTAIN Population}

The design of the CERTAIN study has been published previously [16]. Patients in CERTAIN, recruited from the Corrona RA Registry network $[16,17]$, were enrolled from 43 private practices and academic sites with over 100 participating rheumatologists. CERTAIN included information on 2350 patients, with 10,077 patient visits and a mean patient follow-up time of 10.3 months (median 11.7 months). Patients were included in CERTAIN if they were at least 18 years of age, had at least moderate disease activity (CDAI score $>10$ ) at enrollment, either started therapy (biologic-naïve) with or switched from a prior bDMARD to a TNFi or nonTNFi bDMARD (biologic-experienced) and were followed for 12 months or until they switched/ discontinued bDMARD therapy [16]. Regular data collection at 3-month intervals was mandated in CERTAIN, with uniform collection of anti-CCP status for all patients initiating treatment with a bDMARD.

\section{Analysis Population}

Patients from CERTAIN were included in this analysis if they initiated abatacept or any TNFi (adalimumab, etanercept, certolizumab, golimumab, infliximab), had visits and serum samples available at baseline and 6-month follow-up, had prior bDMARD exposure, and were anti-CCP3+(> $20 \mathrm{U} / \mathrm{ml})$ at baseline.

Propensity Score Matching A propensity score model was used to identify patients with similar disease activity and similar number of prior biologics at baseline in order to determine which serum samples to send for anti-CCP2 testing. Using a logistic regression model with abatacept initiation as the outcome, a propensity score was estimated using baseline CDAI as the only covariate stratified by prior number of biologics: 1 prior biologic and $>1$ prior biologic. Using the propensity score, patients treated with TNFi were matched to patients treated with abatacept, using 1:1 matching based on the propensity score (log odds) with a caliper of 0.025 within each prior biologic strata. Serum samples for 186 abatacept patients and $186 \mathrm{TNFi}$ patients were sent for anti-CCP2 testing. AntiCCP2 levels $\leq 10 \mathrm{U} / \mathrm{ml}$ were defined as negative and those $>10 \mathrm{U} / \mathrm{ml}$ as positive.

\section{Anti-CCP Analysis}

In CERTAIN, there was a uniform collection of specimens for biomarker analysis, thus allowing for simultaneous testing of anti-CCP status at the same time and by a single laboratory for the entire cohort. For this analysis, patients with anti-CCP3 positivity were selected from CERTAIN. Upon enrolment in the CERTAIN database from 2010 to 2014, anti-CCP3 testing was centrally performed on a rolling basis by ICON Laboratories (Farmingdale, NY, USA) who were blinded to the clinical outcomes. Anti-CCP2 is more commonly used in clinical practice than anti-CCP3 and is considered the gold standard. As such, all anti-CCP2 testing was performed on the samples from patients in CERTAIN in a single batch by Exagen Diagnostics (Vista, CA, USA). The patient samples were evaluated in a single batch to minimize variability in processing or reagents that could have occurred over time. Patients who were anti-CCP2+ at baseline $(>10 \mathrm{U} / \mathrm{ml}$ ) were further divided into equal quartiles: quartile $1,11-94 \mathrm{U} / \mathrm{ml}$; quartile 2 , 95-296 U/ml; quartile 3, 297-876 U/ml; and quartile $4,>876 \mathrm{U} / \mathrm{ml}$.

\section{Outcome Measures}

Patient data from baseline and 6-month followup visit were included. All baseline visits and sampling occurred within $36 \mathrm{~h}$ prior to the first dose of the new biologic agent. Variables 
collected at baseline included patient demographics, lifestyle characteristics, disease characteristics, comorbidities, prior medication use, RA disease activity, and PROs. Treatment response by baseline anti-CCP2 quartile was assessed in patients initiating treatment with abatacept or a TNFi.

\section{Primary Outcome}

The primary outcome was change from baseline at 6 months in CDAI score.

\section{Secondary Outcomes}

Secondary outcomes were change from baseline at 6 months in PROs: patient-reported pain and fatigue as measured by visual analog scale (VAS; 0-100), patient global assessment (PtGA; VAS 0-100), and modified Health Assessment Questionnaire (mHAQ; modification of the standard HAQ where the number of activities of daily living was reduced from 20 to 8) score.

\section{Statistical Analysis}

Baseline patient demographics and clinical characteristics were evaluated for abatacept and TNFi groups separately using descriptive statistics across anti-CCP2+ quartiles. Continuous characteristics were evaluated using one-way analysis of variance or Kruskal-Wallis test for characteristics that were not normally distributed. Categorical characteristics were evaluated using the Fisher's exact test. Outcomes were evaluated separately in the abatacept and TNFi groups and were compared across the antiCCP2+ quartiles with a test of trend using anti$\mathrm{CCP} 2+$ quartiles as the ordinal predictor in both unadjusted and adjusted linear regression models. Missing data were not imputed. Patient numbers $<5$ (or $<5$ derived through subtraction from the total) or a percentage of $0 \%$ or $100 \%$ (indicative of certainty) were suppressed due to potential loss of confidentiality. Covariates selected a priori for multivariate adjustment of outcomes included age, sex, CDAI, or PRO score at initiation, modified Charlson Comorbidity Index and current MTX use. Additionally, a sensitivity analysis was conducted using the typical cut-off for anti-CCP
(> $250 \mathrm{U} / \mathrm{ml}$ ) used by commercial laboratories: binary anti-CCP2 cut-offs of $>10-250$ and $>$ $250 \mathrm{U} / \mathrm{ml}$ were used. Similarly, outcomes were evaluated separately in the abatacept and TNFi groups and compared between the binary antiCCP2 cut-offs using anti-CCP2 binary cut-off as the predictor in both unadjusted and adjusted linear regression models. A $P$ value $<0.05$ was considered statistically significant. All statistical analyses were performed using Stata version 15 (StataCorp LLC, College Station, TX, USA).

\section{Patient and Public Involvement}

Study participants were required to provide informed consent for involvement in the study, which included demonstrating full understanding of the study design and outcomes. The research questions and outcome measures were investigated using standard, established physician and patient-derived clinical metrics of disease activity. In addition to implementation of the treatment (which was physician-led as part of routine clinical care), study participants were required to provide the PROs that were key components of the study clinical efficacy evaluation. Patients were not involved in the study design, interpretation, writing or editing of this manuscript but will be informed of the outcomes of the study.

\section{Compliance with Ethics Guidelines}

The study was conducted in accordance with the Declaration of Helsinki and International Conference on Harmonization Good Clinical Practice. The protocol and patients' informed consent received institutional review board/independent ethics committee approval prior to initiation of the study. All participating investigators were required to obtain full board approval for conducting research involving human subjects. Sponsor approval and continuing review was obtained through a central IRB (New England Independent Review Board, NEIRB No. 120160610). For academic investigative sites that did not receive a waiver to use the central IRB, approval was obtained from the respective governing IRBs and documentation 
of approval was submitted to the Sponsor prior to initiating any study procedures. All registry subjects were required to provide written informed consent prior to participating.

\section{RESULTS}

\section{Study Sample}

From CERTAIN, 186 patients initiating abatacept and 557 patients initiating a TNFi met the criteria for inclusion in this post hoc analysis (Fig. 1). In total, 151 biologic-experienced patients initiating treatment with abatacept or a TNFi were included in the analysis. Of these, 13 abatacept- and 14 TNFi-treated patients were anti-CCP2- and 138 and 137 patients were anti-CCP2+, respectively.

At baseline, for patients treated with abatacept who were anti-CCP2+, the majority of patient demographics and disease characteristics were similar across anti-CCP2 quartiles (Table 1). Mean patient age was $56-59$ years, $63-80 \%$ were female, the mean duration of RA was $11.5-13.6$ years, and the mean body mass index (BMI) was $29.2-30.1 \mathrm{~kg} / \mathrm{m}^{2}$. There were significant differences between anti-CCP2 quartiles at baseline for several patient demographics and disease characteristics: mean CDAI score, swollen joint count in 28 joints (SJC28), C-reactive protein (CRP), Disease Activity Score 28 (DAS28) (CRP), RF, mHAQ score, and physician global assessment (all $p<0.05$ ).

At baseline, for patients initiating treatment with a TNFi who were anti-CCP2+, the majority of demographic and disease characteristics were similar across anti-CCP2 quartiles (Table 2). Mean patient age was 55-61 years, $71-78 \%$ were female, the mean duration of RA was 12.1-14.7 years and the mean BMI was $27.4-30.7 \mathrm{~kg} / \mathrm{m}^{2}$. There were significant differences between anti-CCP2 quartiles at baseline in mean RF, mHAQ score, and PtGA (all $p<0.05$ ).

There were no statistically significant differences in medication history and current MTX use at time of initiation across the anti-CCP2 quartiles in either the abatacept or the TNFi treatment groups.

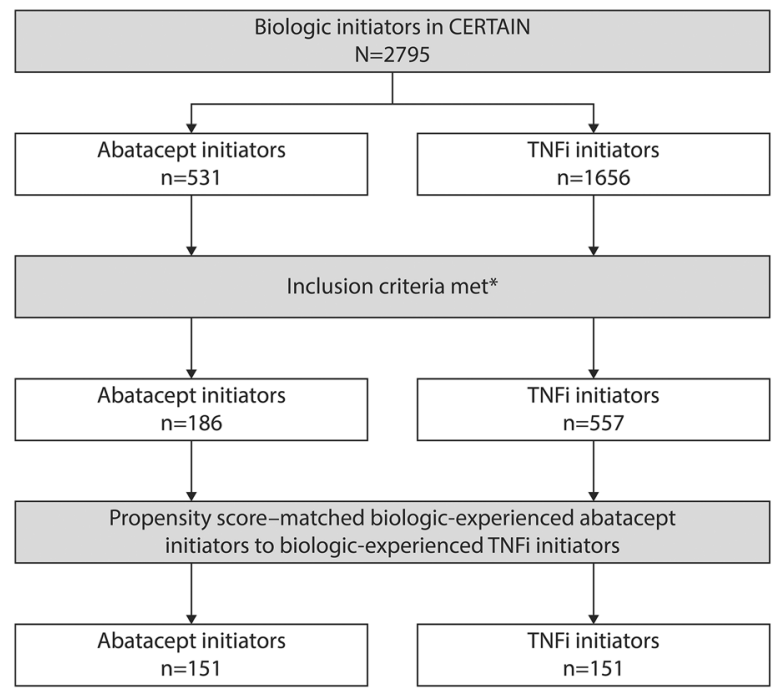

Fig. 1 Patient disposition. *Serum available at baseline and 6-month visit, has 6-month follow-up visit in CERTAIN, moderate or severe CDAI score at baseline visit, CCP3+ at baseline visit. CCP3 cyclic citrullinated peptide 3, CERTAIN Comparative Effectiveness Registry to study Therapies for Arthritis and Inflammatory CoNditions, $T N F i$ tumor necrosis factor inhibitor/s

\section{Clinical and Patient-Reported Outcomes by Anti-CCP2 Quartile}

In the unadjusted model among patients initiating treatment with abatacept, there was a statistically significant improvement in CDAI score and in all PROs (patient-reported pain, fatigue, PtGA, and mHAQ score) across increasing anti-CCP2 quartiles (all $p<0.05$; Supplementary Tables S1 and S2). No relationship was observed between anti-CCP concentration and clinical outcomes or PROs among patients initiating treatment with a TNFi. In the adjusted model, patients initiating treatment with abatacept (Fig. 2), but not those initiating treatment with a TNFi (Fig. 3), demonstrated increasing improvement in CDAI score at 6 months with increasing anti-CCP2 quartile; however, this trend was not statistically significant. In the adjusted model, patients initiating treatment with abatacept, but not those initiating treatment with a TNFi, demonstrated a significantly greater improvement in all PROs at 6 months with increasing anti-CCP2 quartile (Figs. 2 and 3). 
Table 1 Baseline characteristics among abatacept-treated patients by anti-CCP2 quartile

\begin{tabular}{|c|c|c|c|c|c|}
\hline \multirow[t]{2}{*}{ Characteristic } & \multicolumn{5}{|c|}{ Anti-CCP2+, U/ml ${ }^{\mathrm{a}}$} \\
\hline & $\begin{array}{l}\text { Quartile 1 } \\
(n=30)\end{array}$ & $\begin{array}{l}\text { Quartile 2 } \\
(n=37)\end{array}$ & $\begin{array}{l}\text { Quartile 3 } \\
(n=36)\end{array}$ & $\begin{array}{l}\text { Quartile 4 } \\
(n=35)\end{array}$ & $p$ value $^{\mathrm{b}}$ \\
\hline Age, years & $57.7(12.8)$ & $57.2(15.1)$ & $55.8(12.0)$ & $59.0(10.3)$ & 0.754 \\
\hline Female sex, $n(\%)$ & $24(80.0)$ & $26(70.3)$ & $28(77.8)$ & $22(62.9)$ & 0.406 \\
\hline White race, $n(\%)^{\mathrm{c}}$ & $N P^{d}$ & $31(83.8)$ & $N P^{d}$ & $N P^{d}$ & $N P^{d}$ \\
\hline Hispanic ethnicity, $n(\%)^{\mathrm{e}}$ & $\mathrm{NP}^{\mathrm{d}}$ & $\mathrm{NP}^{\mathrm{d}}$ & $\mathrm{NP}^{\mathrm{d}}$ & $5(14.3)$ & $N P^{d}$ \\
\hline BMI, $\mathrm{kg} / \mathrm{m}^{2}$ & $30.1(5.8)$ & $29.2(6.8)$ & $30.1(7.1)$ & $30.1(6.5)$ & 0.879 \\
\hline \multicolumn{6}{|l|}{ Smoking history, $n$ (\%) } \\
\hline Never & $17(56.7)$ & $19(51.4)$ & $14(38.9)$ & $12(34.3)$ & 0.223 \\
\hline Former/Current & $13(43.3)$ & $18(48.6)$ & $22(61.1)$ & $23(65.7)$ & \\
\hline \multicolumn{6}{|l|}{ Comorbidities, $n$ (\%) } \\
\hline Hypertension & $10(33.3)$ & $14(37.8)$ & $13(36.1)$ & $18(51.4)$ & 0.450 \\
\hline Diabetes & $5(16.7)$ & $8(21.6)$ & $1(2.8)$ & $5(14.3)$ & 0.087 \\
\hline Malignancy & $1(3.3)$ & $3(8.1)$ & $2(5.6)$ & $5(14.3)$ & 0.433 \\
\hline Serious infections & $4(13.3)$ & $3(8.1)$ & $6(16.7)$ & $4(11.4)$ & 0.717 \\
\hline Cardiovascular & $6(20.0)$ & $6(16.2)$ & $7(19.4)$ & $4(11.4)$ & 0.780 \\
\hline Duration of RA, years & $11.5(10.3)$ & $13.6(10.7)$ & $12.7(10.3)$ & $12.0(8.3)$ & 0.804 \\
\hline CDAI score & $24.2(9.8)$ & $28.0(12.2)$ & $29.2(11.9)$ & $32.3(12.5)$ & 0.041 \\
\hline TJC28 & $9.4(6.0)$ & $10.1(6.6)$ & $9.4(6.0)$ & $11.9(7.4)$ & 0.437 \\
\hline SJC28 & $5.3(4.3)$ & $7.9(4.6)$ & $9.5(5.9)$ & $9.1(5.4)$ & 0.005 \\
\hline $\mathrm{CRP}, \mathrm{mg} / \mathrm{l}$ & $2.1(1.8)$ & $9.5(14.7)$ & $11.1(13.1)$ & $19.3(19.2)$ & $<0.0001$ \\
\hline DAS28 (CRP) score & $4.3(0.8)$ & $4.8(1.1)$ & $4.8(1.0)$ & $5.3(1.1)$ & 0.004 \\
\hline $\mathrm{RF}, \mathrm{IU} / \mathrm{ml}$ & $110.8(140.8)^{\mathrm{f}}$ & $136.4(163.6)$ & $362.8(672.9)$ & $320.7(380.2)$ & $<0.0001$ \\
\hline mHAQ & $0.6(0.5)$ & $0.4(0.4)$ & $0.6(0.6)$ & $0.7(0.6)$ & 0.049 \\
\hline PtGA (VAS 0-100) & $54.3(28.1)$ & $53.0(23.4)$ & $51.3(29.5)$ & $58.8(29.6)$ & 0.720 \\
\hline PGA (VAS 0-100) & $40.5(18.6)$ & $47.0(20.4)$ & $51.2(18.3)$ & $54.5(20.9)$ & 0.031 \\
\hline $\begin{array}{l}\text { Patient-reported pain (VAS } \\
0-100 \text { ) }\end{array}$ & $53.9(27.8)$ & $51.4(25.4)$ & $52.8(28.0)$ & $65.7(28.9)$ & 0.067 \\
\hline $\begin{array}{l}\text { Patient-reported fatigue (VAS } \\
0-100 \text { ) }\end{array}$ & $59.0(28.1)$ & $55.7(24.1)$ & $54.0(32.1)$ & $58.2(29.0)$ & 0.844 \\
\hline
\end{tabular}


Table 1 continued

\begin{tabular}{|c|c|c|c|c|c|}
\hline \multirow[t]{2}{*}{ Characteristic } & \multicolumn{5}{|c|}{ Anti-CCP2+, U/ml ${ }^{\mathrm{a}}$} \\
\hline & $\begin{array}{l}\text { Quartile 1 } \\
(n=30)\end{array}$ & $\begin{array}{l}\text { Quartile 2 } \\
(n=37)\end{array}$ & $\begin{array}{l}\text { Quartile 3 } \\
(n=36)\end{array}$ & $\begin{array}{l}\text { Quartile 4 } \\
(n=35)\end{array}$ & $p$ value $^{\mathrm{b}}$ \\
\hline \multicolumn{6}{|l|}{ Prior biologic use, $n(\%)$} \\
\hline 1 & $11(36.7)$ & $16(43.2)$ & $9(25.0)$ & $14(40.0)$ & 0.593 \\
\hline 2 & $13(43.3)$ & $13(35.1)$ & $14(38.9)$ & $11(31.4)$ & \\
\hline $3+$ & $6(20.0)$ & $8(21.6)$ & $13(36.1)$ & $10(28.6)$ & \\
\hline Prior TNFi use, $n(\%)^{g}$ & $30(100.0)$ & $35(94.6)$ & $36(100.0)$ & $35(100.0)$ & 0.246 \\
\hline Prior non-TNFi use, $n(\%)^{g}$ & $4(13.3)$ & $8(21.6)$ & $6(16.7)$ & $8(22.9)$ & 0.756 \\
\hline Current MTX use, $n(\%)^{\mathrm{h}}$ & $17(56.7)$ & $20(54.1)$ & $21(58.3)$ & $17(48.6)$ & 0.860 \\
\hline
\end{tabular}

Data are mean $(\mathrm{SD})$, unless otherwise stated

${ }^{a}$ Anti-CCP2 quartiles: quartile 1, 11-94 U/ml; quartile 2, 95-296 U/ml; quartile 3, 297-876 U/ml; and quartile $4,>876 \mathrm{U} / \mathrm{ml}$

${ }^{\mathrm{b}}$ Differences between baseline measures of disease activity across anti-CCP2+ quartiles were assessed using one-way analysis of variance for DAS28 (CRP) and PGA and the Kruskal-Wallis test for nonparametric measures (CDAI, TJC28, SJC28, CRP, RF, mHAQ, and PtGA)

c $n=35$ and 32 for quartiles 3 and 4, respectively

${ }^{\mathrm{d}}$ Patient numbers $<5$ (or $<5$ derived through subtraction from the total) or a percentage of $0 \%$ or $100 \%$ (indicative of certainty) were suppressed (not presented, NP) due to potential loss of confidentiality

e $n=36$ and 35 for quartiles 2 and 3, respectively

f $n=29$

g Prior use reflects all prior biologic history; may not sum to $100 \%$

${ }^{\mathrm{h}}$ At time of biologic initiation

Anti-CCP2 anti-cyclic citrullinated peptide 2, $B M I$ body mass index, $C D A I$ Clinical Disease Activity Index, $C R P$ C-reactive protein, DAS28 (CRP) Disease Activity Score 28 (C-reactive protein), $m H A Q$ modified Health Assessment Questionnaire, $N P$ not presented, $P G A$ physician global assessment, $P t G A$ patient global assessment, $R A$ rheumatoid arthritis, $R F$ rheumatoid factor, $S D$ standard deviation, SJC28 swollen joint count in 28 joints, TJC28 tender joint count in 28 joints, $T N F i$ tumor necrosis factor inhibitor/s, VAS visual analog scale

\section{Sensitivity Analyses}

Sensitivity analyses using binary anti-CCP2 cutoffs $(>10-250$ and $>250 \mathrm{U} / \mathrm{ml}$ ) showed that baseline characteristics were similar to those from the anti-CCP2+ quartile analysis in patients initiating treatment with abatacept or a TNFi (Supplementary Tables S3 and S4). Among patients treated with abatacept, there was a significant improvement in unadjusted CDAI score at 6 months with the higher cut-off versus the lower cut-off $(p<0.05$; Supplementary Table S5). However, the change in CDAI score was no longer statistically significant after adjusting for baseline CDAI score and other covariates $(p=0.186$; Table 3$)$. In addition, among patients treated with abatacept, patientreported pain, fatigue, PtGA, and mHAQ score each showed a significant association with binary anti-CCP2 + status in both unadjusted $(p<0.05$; Supplementary Table S5) and adjusted $(p<0.05$; Table 3$)$ models. Among patients initiating treatment with a TNFi, there was no significant association with binary anti$\mathrm{CCP} 2+$ status for change in CDAI score or PROs in either the unadjusted (Supplementary Table S6) or adjusted (Table 4) models. 
Table 2 Baseline characteristics among TNFi-treated patients by anti-CCP2 quartile

\begin{tabular}{|c|c|c|c|c|c|}
\hline \multirow[t]{2}{*}{ Characteristic } & \multicolumn{5}{|c|}{ Anti-CCP2+, U/ml ${ }^{a}$} \\
\hline & $\begin{array}{l}\text { Quartile 1 } \\
(n=36)\end{array}$ & $\begin{array}{l}\text { Quartile 2 } \\
(n=34)\end{array}$ & $\begin{array}{l}\text { Quartile 3 } \\
(n=32)\end{array}$ & $\begin{array}{l}\text { Quartile 4 } \\
(n=35)\end{array}$ & $p$ value $^{\mathrm{b}}$ \\
\hline Age, years & $60.1(11.5)$ & $60.6(12.7)$ & $55.3(13.3)$ & $58.9(12.5)$ & 0.306 \\
\hline Female sex, $n(\%)$ & $28(77.8)$ & $26(76.5)$ & $24(75.0)$ & $25(71.4)$ & 0.946 \\
\hline White race, $n(\%)^{\mathrm{c}}$ & $N P^{d}$ & $N P^{d}$ & $24(82.8)$ & $N P^{d}$ & $N P^{d}$ \\
\hline Hispanic ethnicity, $n(\%)^{\mathrm{e}}$ & $\mathrm{NP}^{\mathrm{d}}$ & $\mathrm{NP}^{\mathrm{d}}$ & $\mathrm{NP}^{\mathrm{d}}$ & $5(15.2)$ & $N P^{d}$ \\
\hline BMI, $\mathrm{kg} / \mathrm{m}^{2}$ & $30.7(9.0)$ & $27.4(6.0)$ & $28.6(6.5)$ & $29.3(7.7)$ & 0.611 \\
\hline \multicolumn{6}{|l|}{ Smoking history, $n(\%)^{\mathrm{f}}$} \\
\hline Never & $21(58.3)$ & $12(36.4)$ & $16(53.3)$ & $14(40.0)$ & 0.213 \\
\hline Former/Current & $15(41.7)$ & $21(63.6)$ & $14(46.7)$ & $21(60.0)$ & \\
\hline \multicolumn{6}{|l|}{ Comorbidities, $n$ (\%) } \\
\hline Hypertension & $17(47.2)$ & $10(29.4)$ & $9(28.1)$ & $15(42.9)$ & 0.263 \\
\hline Diabetes & $4(11.1)$ & $3(8.8)$ & $1(3.1)$ & $2(5.7)$ & 0.683 \\
\hline Malignancy & $1(2.8)$ & $2(5.9)$ & $1(3.1)$ & $3(8.6)$ & 0.748 \\
\hline Serious infections & $3(8.3)$ & $4(11.8)$ & $2(6.3)$ & $4(11.4)$ & 0.885 \\
\hline Cardiovascular & $4(11.1)$ & $3(8.8)$ & $6(18.8)$ & $4(11.4)$ & 0.681 \\
\hline Duration of RA, years & $14.1(9.6)$ & $14.7(13.7)$ & $12.1(8.2)$ & $13.1(9.3)$ & 0.897 \\
\hline CDAI score & $29.1(10.8)$ & $32.3(12.5)$ & $26.2(11.2)$ & $29.8(13.7)$ & 0.255 \\
\hline TJC28 & $11.3(7.2)$ & $11.9(6.3)$ & $9.6(6.1)$ & $11.0(7.1)$ & 0.537 \\
\hline SJC28 & $7.6(4.6)$ & $9.4(5.9)$ & $7.4(4.2)$ & $7.6(6.0)$ & 0.427 \\
\hline $\mathrm{CRP}, \mathrm{mg} / \mathrm{l}$ & $15.5(30.8)$ & $17.1(24.3)$ & $12.2(14.2)^{\mathrm{g}}$ & $13.3(27.0)$ & 0.966 \\
\hline DAS28 (CRP) & $4.9(1.1)$ & $5.1(1.0)$ & $4.6(1.0)^{\mathrm{g}}$ & $4.9(1.2)$ & 0.315 \\
\hline $\mathrm{RF}, \mathrm{IU} / \mathrm{ml}^{\mathrm{h}}$ & $111.0(173.2)$ & $182.9(353.3)$ & $342.0(559.1)$ & $617.8(1042.6)$ & $<0.0001$ \\
\hline mHAQ & $0.5(0.4)$ & $0.6(0.6)$ & $0.3(0.3)$ & $0.8(0.6)$ & 0.003 \\
\hline PtGA (VAS 0-100) & $50.4(23.3)$ & $57.1(22.5)$ & $40.5(27.2)$ & $59.4(24.8)$ & 0.012 \\
\hline PGA (VAS 0-100) & $52.1(14.5)$ & $52.9(17.4)$ & $51.3(19.8)$ & $51.9(19.2)$ & 0.987 \\
\hline $\begin{array}{l}\text { Patient-reported pain (VAS } \\
0-100 \text { ) }\end{array}$ & $54.8(28.3)$ & $56.8(26.4)$ & $45.4(26.3)$ & $60.8(26.4)$ & 0.136 \\
\hline $\begin{array}{l}\text { Patient-reported fatigue (VAS } \\
0-100 \text { ) }\end{array}$ & $51.6(29.4)$ & $51.7(29.7)$ & $47.4(29.8)$ & $58.2(28.7)$ & 0.463 \\
\hline
\end{tabular}


Table 2 continued

\begin{tabular}{|c|c|c|c|c|c|}
\hline \multirow[t]{2}{*}{ Characteristic } & \multicolumn{5}{|c|}{ Anti-CCP2+, $\mathrm{U} / \mathrm{ml}^{\mathrm{a}}$} \\
\hline & $\begin{array}{l}\text { Quartile 1 } \\
(n=36)\end{array}$ & $\begin{array}{l}\text { Quartile 2 } \\
(n=34)\end{array}$ & $\begin{array}{l}\text { Quartile } 3 \\
(n=32)\end{array}$ & $\begin{array}{l}\text { Quartile 4 } \\
(n=35)\end{array}$ & $p$ value $^{\mathrm{b}}$ \\
\hline \multicolumn{6}{|l|}{ Prior biologic use, $n(\%)$} \\
\hline 1 & $14(38.9)$ & $15(44.1)$ & $13(40.6)$ & $14(40.0)$ & 0.821 \\
\hline 2 & $13(36.1)$ & $8(23.5)$ & $13(40.6)$ & $12(34.3)$ & \\
\hline $3+$ & $9(25.0)$ & $11(32.4)$ & $6(18.8)$ & $9(25.7)$ & \\
\hline Prior TNFi use, $n(\%)^{\mathrm{i}}$ & $34(94.4)$ & $34(100.0)$ & $31(96.9)$ & $34(97.1)$ & 0.747 \\
\hline Prior non-TNFi use, $n(\%)^{\mathrm{i}}$ & $15(41.7)$ & $14(41.2)$ & $9(28.1)$ & $13(37.1)$ & 0.645 \\
\hline Prior abatacept use, $n(\%)^{\mathrm{i}}$ & $11(30.6)$ & $12(35.3)$ & $6(18.8)$ & $11(31.4)$ & 0.485 \\
\hline Current MTX use, $n(\%)^{j}$ & $21(58.3)$ & $18(52.9)$ & $20(62.5)$ & $19(54.3)$ & 0.868 \\
\hline
\end{tabular}

Data are mean $(\mathrm{SD})$, unless otherwise stated

a Anti-CCP2 quartiles: quartile 1, 11-94 U/ml; quartile 2, 95-296 U/ml; quartile 3, 297-876 U/ml; and quartile $4,>876 \mathrm{U} / \mathrm{ml}$

b Differences between baseline measures of disease activity across anti-CCP2+ quartiles were assessed using one-way analysis of variance for DAS28 (CRP) and PGA and the Kruskal-Wallis test for nonparametric measures (CDAI, TJC28, SJC28, CRP, RF, mHAQ and PtGA)

c $n=29$ and 34 for quartiles 3 and 4, respectively

d Patient numbers $<5$ (or $<5$ derived through subtraction from the total) or a percentage of $0 \%$ or $100 \%$ (indicative of certainty) were suppressed (not presented, NP) due to potential loss of confidentiality

e $n=35$ and 33 for quartiles 1 and 4, respectively

${ }^{\mathrm{f}} n=33$ and 30 for quartiles 2 and 3 , respectively

g $n=31$

h $n=35,32,31$, and 34 for quartiles 1 to 4 , respectively

i Prior use reflects all prior biologic history; may not sum to $100 \%$

j At time of biologic initiation

Anti-CCP2 anti-cyclic citrullinated peptide 2, BMI body mass index, $C D A I$ Clinical Disease Activity Index, CRP C-reactive protein, DAS28 (CRP) Disease Activity Score in 28 joints (C-reactive protein), $m H A Q$ modified Health Assessment Questionnaire, MTX methotrexate, $P G A$ physician global assessment; PtGA patient global assessment, RA rheumatoid arthritis, $R F$ rheumatoid factor, $S D$ standard deviation, $S J C 28$ swollen joint count in 28 joints, TJC28 tender joint count in 28 joints, $T N F i$ tumor necrosis factor inhibitor/s, VAS visual analog scale

\section{DISCUSSION}

In this prospective, adjusted analysis of biologic-experienced patients with RA, higher (versus lower) anti-CCP2 concentrations at baseline were associated with a numerically greater improvement in CDAI score and significantly greater improvements in PROs after 6 months of treatment with abatacept. No association between baseline anti-CCP2 concentration and treatment response was observed in patients treated with a TNFi.
Baseline disease characteristics (CDAI score, SJC28, CRP, DAS28 [CRP], RF, mHAQ score, physician global assessment) were significantly different between anti-CCP2 levels for patients initiating abatacept. For patients initiating a TNFi, RF, mHAQ score and PtGA were significantly different between anti-CCP2 levels. The association of increased baseline disease characteristics with a higher baseline anti-CCP2 titer (compared with a lower baseline anti-CCP2) in patients is consistent with previous research where patients with high levels of 

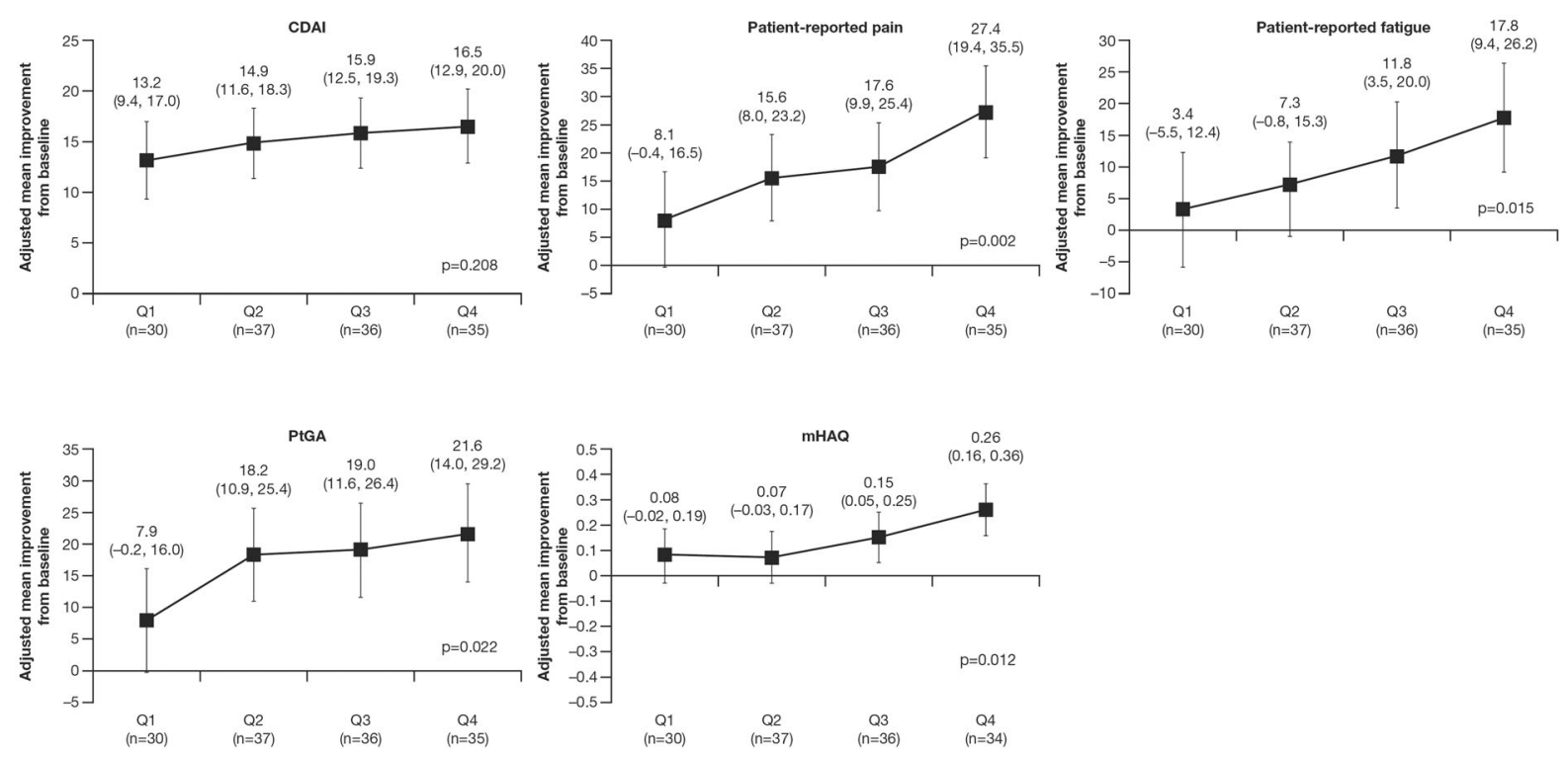

Fig. 2 Adjusted mean improvement from baseline* in CDAI score and PROs for abatacept-treated patients, by anti-CCP2 quartile. Data are mean (95\% CI); quartile 1 $(n=30)$ was used as the reference. *Adjusted for age, sex, baseline CDAI score or PROs, Charlson Comorbidity

Index and current methotrexate use. Anti-CCP2 anti-cyclic citrullinated peptide 2, CDAI Clinical Disease Activity Index, $C I$ confidence interval, $m H A Q$ modified Health Assessment Questionnaire, PRO patient-reported outcome, $P t G A$ patient global assessment, $Q$ quartile
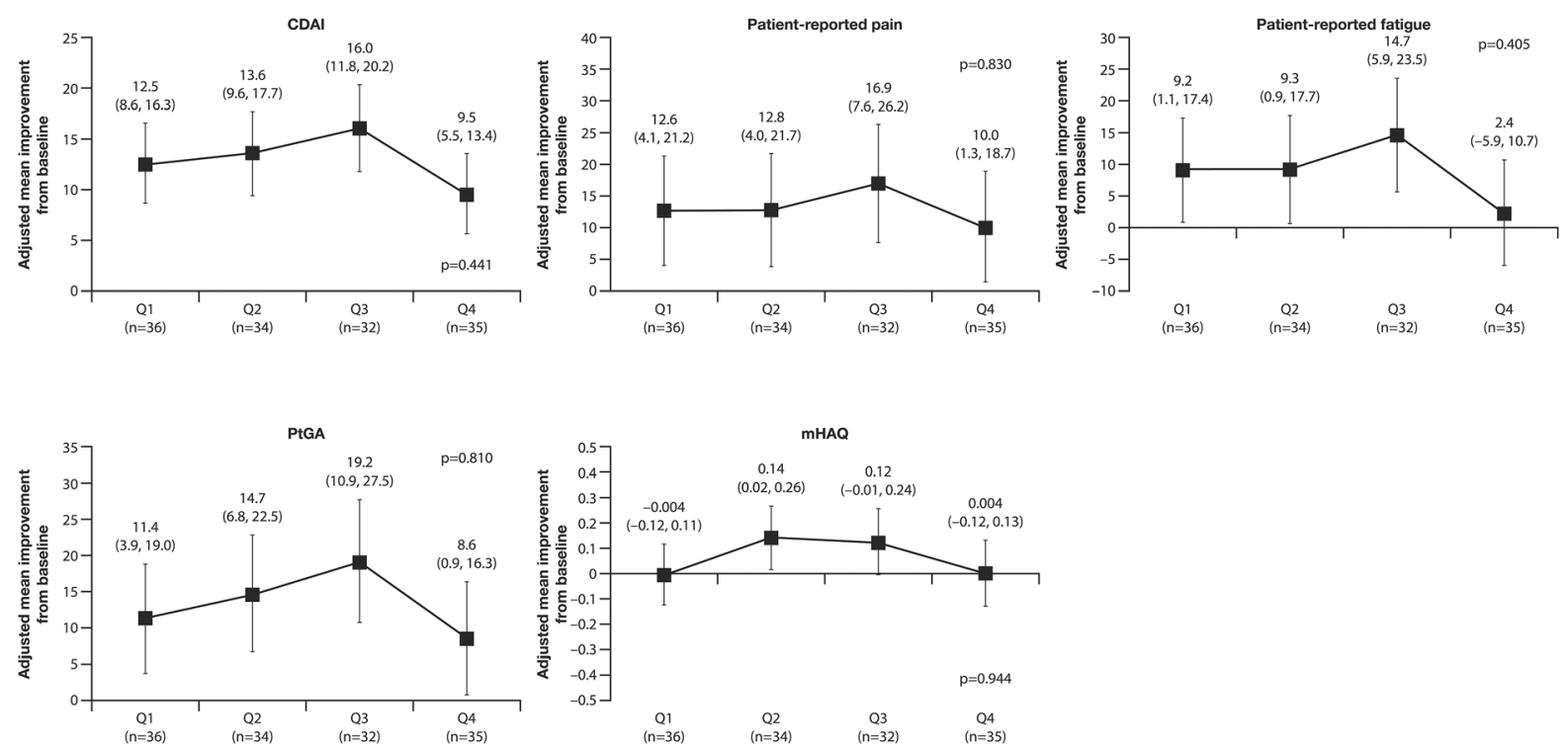

Fig. 3 Adjusted mean improvement from baseline* in CDAI score and PROs for TNFi-treated patients, by antiCCP2 quartile. Data are mean ( $95 \% \mathrm{CI})$; quartile 1 $(n=36)$ was used as the reference. ${ }^{*}$ Adjusted for age, sex, baseline CDAI score or PROs, Charlson Comorbidity citrullinated peptide 2, CDAI Clinical Disease Activity Index, $C I$ confidence interval, $m H A Q$ modified Health Assessment Questionnaire, PRO patient-reported outcome, PtGA patient global assessment, $Q$ quartile, $T N F i$ tumor necrosis factor inhibitor/s 
Table 3 Adjusted mean improvement from baseline in CDAI score and PROs for abatacept-treated patients, by binary anti-CCP2 cut-off

\begin{tabular}{|c|c|c|c|}
\hline $\begin{array}{l}\text { Full adjusted } \\
\text { outcome }\end{array}$ & $\begin{array}{l}\text { Anti- } \\
\text { CCP2+ } \\
>10-250 \\
\mathrm{U} / \mathrm{ml} \\
(n=61)\end{array}$ & $\begin{array}{l}\text { Anti- } \\
\text { CCP2+ } \\
>250 \\
\mathrm{U} / \mathrm{ml} \\
(n=77)\end{array}$ & $p$ value \\
\hline $\begin{array}{l}\Delta \text { CDAI, mean } \\
(95 \% \mathrm{CI})\end{array}$ & $\begin{array}{c}13.9(11.2, \\
16.5)\end{array}$ & $\begin{array}{c}16.3 \\
(13.9 \\
18.6)\end{array}$ & 0.186 \\
\hline $\begin{array}{l}\Delta \text { mHAQ, mean } \\
(95 \% \mathrm{CI})\end{array}$ & $\begin{array}{l}0.07 \\
\quad(-0.01 \\
0.14)\end{array}$ & $\begin{array}{l}0.20 \\
(0.13 \\
0.27)^{\mathrm{a}}\end{array}$ & 0.014 \\
\hline $\begin{array}{l}\Delta \text { patient-reported } \\
\text { pain, mean } \\
(95 \% \mathrm{CI})\end{array}$ & $\begin{array}{c}11.1(5.1 \\
17.0)\end{array}$ & $\begin{array}{l}22.6 \\
(17.3 \\
27.9)\end{array}$ & 0.005 \\
\hline $\begin{array}{l}\Delta \text { patient-reported } \\
\text { fatigue, mean } \\
(95 \% \mathrm{CI})\end{array}$ & $\begin{array}{c}4.6(-1.7 \\
10.9)\end{array}$ & $\begin{array}{c}14.8(9.2 \\
20.3)\end{array}$ & 0.018 \\
\hline $\begin{array}{l}\Delta \text { patient global } \\
\text { assessment, mean } \\
(95 \% \mathrm{CI})\end{array}$ & $\begin{array}{c}12.6(6.9 \\
18.3)\end{array}$ & $\begin{array}{l}20.5 \\
(15.5 \\
25.6)\end{array}$ & 0.042 \\
\hline
\end{tabular}

Anti-CCP2 $>10-250 \mathrm{U} / \mathrm{ml}$ was used as the reference. Adjusted for age, sex, baseline CDAI score or PROs, comorbidity index and current methotrexate use.

Anti-CCP2 anti-cyclic citrullinated peptide 2, CDAI Clinical Disease Activity Index, $C I$ confidence interval, $m H A Q$ modified Health Assessment Questionnaire, PRO patient-reported outcome

a $n=76$ for mHAQ

autoantibodies, including ACPA, have higher disease activity and greater impairment of physical function $[3,4,6]$.

In the adjusted model, the CDAI score was numerically improved and PROs were significantly improved after 6 months across both increasing anti-CCP2 quartiles and binary cutoffs for patients treated with abatacept. There were no significant improvements in CDAI score or PROs across anti-CCP2 quartiles or binary cut-offs for patients initiating a TNFi. Data from previous clinical trials have shown an
Table 4 Adjusted mean improvement from baseline in CDAI score and PROs for TNFi-treated patients, by binary anti-CCP2 cut-off

\begin{tabular}{|c|c|c|c|}
\hline $\begin{array}{l}\text { Full adjusted } \\
\text { outcome }\end{array}$ & $\begin{array}{l}\text { Anti- } \\
\text { CCP2+ } \\
>10-250 \\
\mathrm{U} / \mathrm{ml} \\
(n=63)\end{array}$ & $\begin{array}{l}\text { Anti- } \\
\text { CCP2+ } \\
>250 \\
\mathrm{U} / \mathrm{ml} \\
(n=74)\end{array}$ & $p$ value \\
\hline $\begin{array}{c}\Delta \mathrm{CDAI} \text {, mean } \\
(95 \% \mathrm{CI})\end{array}$ & $\begin{array}{c}13.1(10.2 \\
16.1)\end{array}$ & $\begin{array}{c}12.6(9.8 \\
15.3)\end{array}$ & 0.776 \\
\hline $\begin{array}{c}\Delta \text { mHAQ, mean } \\
(95 \% \mathrm{CI})\end{array}$ & $\begin{array}{l}0.08 \\
\quad(-0.01 \\
0.17)\end{array}$ & $\begin{array}{l}0.04 \\
\quad(-0.04, \\
0.13)\end{array}$ & 0.563 \\
\hline $\begin{array}{l}\Delta \text { patient-reported } \\
\text { pain, mean } \\
(95 \% \mathrm{CI})\end{array}$ & $\begin{array}{c}13.0(6.5 \\
19.4)\end{array}$ & $\begin{array}{c}13.1(7.1 \\
19.0)\end{array}$ & 0.985 \\
\hline $\begin{array}{l}\Delta \text { patient-reported } \\
\text { fatigue, mean } \\
(95 \% \mathrm{CI})\end{array}$ & $\begin{array}{c}10.7(4.5, \\
16.9)\end{array}$ & $\begin{array}{c}7.1(1.4, \\
12.8)\end{array}$ & 0.404 \\
\hline $\begin{array}{l}\Delta \text { patient global } \\
\text { assessment, mean } \\
(95 \% \mathrm{CI})\end{array}$ & $\begin{array}{c}13.4(7.7 \\
19.2)\end{array}$ & $\begin{array}{c}13.2(7.9 \\
18.5)\end{array}$ & 0.956 \\
\hline
\end{tabular}

Anti-CCP2 $>10-250 \mathrm{U} / \mathrm{ml}$ was used as the reference. Adjusted for age, sex, baseline CDAI score or PROs, comorbidity index and current methotrexate use.

Anti-CCP2 anti-cyclic citrullinated peptide 2, CDAI Clinical Disease Activity Index, $C I$ confidence interval, $m H A Q$ modified Health Assessment Questionnaire, PRO patient-reported outcome, TNFi tumor necrosis factor inhibitor/s

association between ACPA+ status and clinical response to abatacept, in combination with MTX, in both bDMARD-naïve patients (AMPLE) [13] and MTX-naïve patients with very early RA (AVERT; Assessing Very Early Rheumatoid arthritis Treatment) $[18,19]$. In a post hoc analysis of the AMPLE trial, a more pronounced treatment effect was observed in patients with higher baseline anti-CCP titers compared with lower titers [13]. Furthermore, some studies suggest that treatment with abatacept in combination with MTX may lead to a reduction in autoantibody levels over time, and that conversion to ACPA seronegative status may be 
associated with better clinical outcomes $[20,21]$. Consistent data from real-world studies have also been observed. In the ACTION (AbataCepT In rOutiNe clinical practice) study, RF/ anti-CCP+ status was associated with greater clinical effectiveness and retention on treatment in patients receiving abatacept [22]. Analyses from the Corrona RA Registry [14] and a pan-European registry [23] have shown greater effectiveness with abatacept in patients who were $\mathrm{ACPA}+$ or $\mathrm{ACPA}+/ \mathrm{RF}+$, respectively. Additionally, a meta-analysis of 18 studies showed ACPA positivity to be associated with better EULAR responses in patients receiving abatacept but not in those receiving a TNFi [24].

A major genetic risk factor for RA is the shared epitope (SE), which is located on the $\beta 1$ chain of the human leukocyte antigen-DR major histocompatibility complex Class II cellsurface receptor $[25,26]$. SE is associated with the production of ACPAs in patients with RA (the majority of patients with anti-CCP+RA also exhibit SE) [27], and studies have shown an association between SE and increased disease activity [26, 28, 29]. Additionally, abatacept has significantly higher clinical efficacy among patients with SE+RA compared with SE-RA $[30,31]$. Ongoing studies are exploring the impact of SE on treatment outcomes.

This study has several strengths. Corrona is a US-based registry, which includes a large number of patients with RA with validated outcome measures and is representative of patients found in clinical practice in the US [32]. Previous analyses have compared Medicare patients with RA enrolled in Corrona to those not part of the registry and have found similar demographic and comorbidity characteristics, supporting the generalizability of the Corrona registry [32]. Although the Corrona RA Registry patient population is managed by rheumatologists across the US, with no centralized laboratory testing for serological status, all patients derived from the CERTAIN study had centralized measurement of CCP status. Data were collected prospectively at patient visits; therefore, differential bias in responses by treatment assignment were not expected. The results from the current study complement those of previous studies that have provided data regarding the clinical effectiveness of abatacept in patients with RA who were anti-CCP+ at baseline $[13,14,18,19,21,22,30,31]$. Our study is methodologically strong: In contrast to previous studies [14, 18, 19, 21, 22, 30, 31], patients were grouped into anti-CCP2 quartiles (quartile 1, 11-94 U/ml; quartile 2, 95-296 U/ml; quartile $3,297-876 \mathrm{U} / \mathrm{ml}$; and quartile $4,>876 \mathrm{U} / \mathrm{ml}$ ) and we sought to correlate outcomes by quartile. We also performed a sensitivity analysis using the typical laboratory cut-off points for baseline anti-CCP2 available to physicians (> 10-250 U/ml and $>250 \mathrm{U} / \mathrm{ml}$ ). Additionally, we compared the utility of anti-CCP status with TNFi treatment. As such, our study provides real-world, clinically relevant evidence that may assist clinicians in making more informed individualized treatment decisions taking into account the effect of ACPA status on treatment response [4].

As with all real-world studies, there are limitations to our study. Patients included in the registry were diagnosed by different rheumatologists across the US. Treatment selection in any real-world setting is not random, as physicians are influenced by a number of factors when prescribing treatments, including individual patient profiles. However, to help offset such potential selection bias, propensity score matching was used in the present study to identify patients with similar disease activity within each line of therapy prior to anti-CCP2 testing. The study sample size was relatively small, and the duration of follow-up (6 months) was relatively short. Treatments were not blinded; as such, patients may have been aware if they were treated with a new class of biologic, which may have influenced PROs and CDAI scores.

\section{CONCLUSIONS}

In conclusion, among bDMARD-experienced patients with RA initiating treatment with abatacept, but not a TNFi, higher anti-CCP2 concentrations at baseline were associated with numerically, but not statistically, greater improvements in CDAI score and significantly greater improvement in PROs in the adjusted 
model after 6 months of treatment. This association was not observed in a similar sample size of patients initiating treatment with TNFi. The association between genetic factors and treatment outcome in patients with RA is under further investigation.

\section{ACKNOWLEDGEMENTS}

The authors would like to thank all of the participating providers and patients for contributing data to Corrona CERTAIN.

Funding. This study was sponsored by CorEvitas, LLC, and the analysis and the journal's Rapid Service Fee were funded by Bristol Myers Squibb. Only CorEvitas had access to the study data and CorEvitas statisticians completed all of the analysis; all authors contributed to the interpretation of the results. CorEvitas has been supported through contracted subscriptions in the last 2 years by AbbVie, Amgen, Boehringer Ingelheim, Bristol Myers Squibb, Celgene, Chugai, Eli Lilly and Company, Genentech, Gilead, Janssen, Novartis, Ortho Dermatologics, Pfizer Inc., Regeneron, Sanofi, Sun, and UCB.

Medical Writing, Editorial, and Other Assistance. Professional medical writing and editorial assistance was provided by Claire Line, PhD, and Rachel Rankin, PhD, at Caudex. Support for this assistance was funded by Bristol Myers Squibb.

Authorship. All named authors meet the International Committee of Medical Journal Editors criteria for authorship for this article, take responsibility for the integrity of the work as a whole, and have given their approval for this version to be published.

Author Contributions. The design and study conduct were a collaborative effort between CorEvitas, LLC and Bristol Myers Squibb; all authors reviewed and interpreted the study results and data. However, access to study data was limited to CorEvitas, LLC: CorEvitas statisticians completed all analyses. All authors drafted the article or critically revised the article for important intellectual content. All authors were involved in the decision to submit the article for publication and approved the final version of the article for submission.

Prior Presentation. These data were previously presented at ACR 2019 (Harrold L, Bryson J, Lehman T, et al. Arthritis Rheumatol 2019;71(suppl 10):abstract 1394). The poster was a collaborative effort between CorEvitas and Bristol Myers Squibb, with financial support provided by Bristol Myers Squibb.

Disclosures. Leslie R. Harrold: shareholder: CorEvitas, LLC; grant/research support: Pfizer; consulting fees: AbbVie, Bristol Myers Squibb and Roche. Joshua Bryson, Thomas Lehman, Joe Zhuo, Sheng Gao, Xue Han: employees and shareholders: Bristol Myers Squibb. Amy Schrader, Sabrina Rebello, * Tanya Sommers: employees: CorEvitas, LLC. Dimitrios A. Pappas: employee and shareholder: CorEvitas, LLC; serving on the board of directors of CorEvitas Research Foundation; consulting honoraria from Novartis, Genentech/Roche, AbbVie and Sanofi. Joel M. Kremer: shareholder: CorEvitas, LLC; grant/research support: AbbVie, Bristol Myers Squibb, Eli Lilly, Novartis, Pfizer; consulting fees: AbbVie, Bristol Myers Squibb, Eli Lilly, Gilead and Pfizer. *At the time of analysis; current affiliation: Amyloidosis Research Consortium, 320 Nevada Street, Suite 210, Newton, MA.

Compliance with Ethics Guidelines. The study was conducted in accordance with the Declaration of Helsinki and International Conference on Harmonization Good Clinical Practice. The protocol and patient's informed consent received institutional review board/independent ethics committee approval prior to initiation of the study. All participating investigators were required to obtain full board approval for conducting research involving human subjects. Sponsor approval and continuing review was obtained through a central IRB (New England Independent Review Board, NEIRB No. 120160610). For academic 
investigative sites that did not receive a waiver to use the central IRB, approval was obtained from the respective governing IRBs and documentation of approval was submitted to the Sponsor prior to initiating any study procedures. All registry subjects were required to provide written informed consent prior to participating.

Data Availability. The Corrona RA Registry dataset is based on a large US multicenter study adhering to a number of institutional review boards, with complex logistics. Patients did not provide consent to raw data sharing during the data collection for this purpose, and the CorEvitas data sharing policies do not permit raw data sharing for this purpose. An aggregated limited dataset from the current analyses is available to qualified investigators with an approved protocol. Data requests may be sent to CorEvitas, represented by Dr. Jeffrey D. Greenberg, MD, MPH, NYU School of Medicine, New York, NY, e-mail jgreenberg@corevitas.com.

Open Access. This article is licensed under a Creative Commons Attribution-NonCommercial 4.0 International License, which permits any non-commercial use, sharing, adaptation, distribution and reproduction in any medium or format, as long as you give appropriate credit to the original author(s) and the source, provide a link to the Creative Commons licence, and indicate if changes were made. The images or other third party material in this article are included in the article's Creative Commons licence, unless indicated otherwise in a credit line to the material. If material is not included in the article's Creative Commons licence and your intended use is not permitted by statutory regulation or exceeds the permitted use, you will need to obtain permission directly from the copyright holder. To view a copy of this licence, visit http://creativecommons.org/licenses/by$\mathrm{nc} / 4.0 /$.

\section{REFERENCES}

1. Scott DL, Wolfe F, Huizinga TW. Rheumatoid arthritis. Lancet. 2010;376:1094-108.

2. Kurowska W, Kuca-Warnawin EH, Radzikowska A, Maslinski $\mathrm{W}$. The role of anti-citrullinated protein antibodies (ACPA) in the pathogenesis of rheumatoid arthritis. Cent Eur J Immunol. 2017;42:390-8.

3. van der Helm-van Mil AHM, Verpoort KN, Breedveld FC, Toes RE, Huizinga TW. Antibodies to citrullinated proteins and differences in clinical progression of rheumatoid arthritis. Arthritis Res Ther. 2005; 7:R949-58.

4. Smolen JS, Landewe RBM, Bijlsma JWJ, et al. EULAR recommendations for the management of rheumatoid arthritis with synthetic and biological disease-modifying antirheumatic drugs: 2019 update. Ann Rheum Dis. 2020;79:685-99.

5. Hecht C, Englbrecht M, Rech J, et al. Additive effect of anti-citrullinated protein antibodies and rheumatoid factor on bone erosions in patients with RA. Ann Rheum Dis. 2015;74:2151-6.

6. Katchamart W, Koolvisoot A, Aromdee E, Chiowchanwesawakit P, Muengchan C. Associations of rheumatoid factor and anti-citrullinated peptide antibody with disease progression and treatment outcomes in patients with rheumatoid arthritis. Rheumatol Int. 2015;35:1693-9.

7. Ajeganova S, Humphreys JH, Verheul $\mathrm{MK}$, et al. Anticitrullinated protein antibodies and rheumatoid factor are associated with increased mortality but with different causes of death in patients with rheumatoid arthritis: a longitudinal study in three European cohorts. Ann Rheum Dis. 2016;75: 1924-32.

8. Singh JA, Saag KG, Bridges SL Jr, et al. 2015 American College of Rheumatology guideline for the treatment of rheumatoid arthritis. Arthritis Care Res. 2016;68:1-26.

9. Ma MH, Scott IC, Dahanayake C, Cope AP, Scott DL. Clinical and serological predictors of remission in rheumatoid arthritis are dependent on treatment regimen. J Rheumatol. 2014;41:1298-303.

10. Nüßlein HG, Alten R, Galeazzi M, et al. Prognostic factors for abatacept retention in patients who received at least one prior biologic agent: an interim analysis from the observational, prospective ACTION study. BMC Musculoskelet Disord. $2015 ; 16: 176$

11. Schellekens GA, de Jong BA, van den Hoogen FH, van de Putte LB, van Venrooij WJ. Citrulline is an 
essential constituent of antigenic determinants recognized by rheumatoid arthritis-specific autoantibodies. J Clin Invest. 1998;101:273-81.

12. Vos I, Van Mol C, Trouw LA, et al. Anti-citrullinated protein antibodies in the diagnosis of rheumatoid arthritis (RA): diagnostic performance of automated anti-CCP-2 and anti-CCP-3 antibodies assays. Clin Rheumatol. 2017;36:1487-92.

13. Sokolove J, Schiff M, Fleischmann R, et al. Impact of baseline anti-cyclic citrullinated peptide 2 antibody titre on efficacy outcomes following treatment with subcutaneous abatacept or adalimumab: 2-year results from the AMPLE trial. Ann Rheum Dis. 2015;74:983-4.

14. Harrold LR, Litman HJ, Connolly SE, et al. Effect of anticitrullinated protein antibody status on response to abatacept or antitumor necrosis factoralpha therapy in patients with rheumatoid arthritis: a US national observational study. J Rheumatol. 2018;45:32-9.

15. Chatzidionysiou K, Lie E, Nasonov E, et al. Highest clinical effectiveness of rituximab in autoantibodypositive patients with rheumatoid arthritis and in those for whom no more than one previous TNF antagonist has failed: pooled data from 10 European registries. Ann Rheum Dis. 2011;70:1575-80.

16. Pappas DA, Kremer JM, Reed G, Greenberg JD, Curtis JR. Design characteristics of the CORRONA CERTAIN study: a comparative effectiveness study of biologic agents for rheumatoid arthritis patients. BMC Musculoskelet Disord. 2014;15:113.

17. Harrold LR, Litman HJ, Connolly SE, et al. Comparative effectiveness of abatacept versus tumor necrosis factor inhibitors in patients with rheumatoid arthritis who are anti-CCP positive in the United States Corrona Registry. Rheumatol Ther. 2019;6:217-30.

18. Huizinga TWJ, Connolly SE, Johnsen A, et al. Effect of anti-cyclic citrullinated peptide 2 immunoglobulin $\mathrm{M}$ serostatus on efficacy outcomes following treatment with abatacept plus methotrexate in the AVERT trial. Ann Rheum Dis. 2015;74(Suppl 2): 234-5.

19. Peterfy C, Burmester G, Bykerk VP, et al. Sustained improvements in magnetic resonance imaging outcomes with abatacept following the withdrawal of all treatment in patients with early rheumatoid arthritis. Arthritis Rheum. 2014;66:S669.

20. Jansen DTSL, Emery P, Smolen JS, et al. Conversion to seronegative status after abatacept treatment in patients with early and poor prognostic rheumatoid arthritis is associated with better radiographic outcomes and sustained remission: post hoc analysis of the AGREE study. RMD Open. 2018;4: e000654.

21. Alessandri C, Bombardieri $\mathrm{M}$, Papa $\mathrm{N}$, et al. Decrease of anti-cyclic citrullinated peptide antibodies and rheumatoid factor following antiTNFalpha therapy (infliximab) in rheumatoid arthritis is associated with clinical improvement. Ann Rheum Dis. 2004;63:1218-21.

22. Alten R, Nüßlein HG, Mariette $X$, et al. Baseline autoantibodies preferentially impact abatacept efficacy in patients with rheumatoid arthritis who are biologic naive: 6-month results from a realworld, international, prospective study. RMD Open. 2017;3:e000345.

23. Gottenberg JE, Courvoisier DS, Hernandez MV, et al. Brief report: association of rheumatoid factor and anti-citrullinated protein antibody positivity with better effectiveness of abatacept: results from the pan-European registry analysis. Arthritis Rheumatol. 2016;68:1346-52.

24. Alemao E, Postema R, Elbez Y, Mamane C, Finckh A. Presence of anti-cyclic citrullinated peptide antibodies is associated with better treatment response to abatacept but not to TNF inhibitors in patients with rheumatoid arthritis: a meta-analysis. Clin Exp Rheumatol. 2020;38:455-66.

25. Trowsdale J. Genomic structure and function in the MHC. Trends Genet. 1993;9:117-22.

26. Klareskog L, Stolt P, Lundberg K, et al. A new model for an etiology of rheumatoid arthritis: smoking may trigger HLA-DR (shared epitope)-restricted immune reactions to autoantigens modified by citrullination. Arthritis Rheum. 2006;54:38-46.

27. Jiang X, Frisell T, Askling J, et al. To what extent is the familial risk of rheumatoid arthritis explained by established rheumatoid arthritis risk factors? Arthritis Rheumatol. 2015;67:352-62.

28. Lundstrom E, Kallberg H, Alfredsson L, Klareskog L, Padyukov L. Gene-environment interaction between the DRB1 shared epitope and smoking in the risk of anti-citrullinated protein antibody-positive rheumatoid arthritis: all alleles are important. Arthritis Rheum. 2009;60:1597-603.

29. Alemao E, Bryson J, Iannaccone CK, Frits M, Shadick NA, Weinblatt M. Association of shared epitope and poor prognostic factors in RA. Arthritis Rheumatol. 2018;70:abstract 71.

30. Oryoji K, Yoshida K, Kashiwado Y, et al. Shared epitope positivity is related to efficacy of abatacept in rheumatoid arthritis. Ann Rheum Dis. 2018;77: 1234-6. 
31. Rigby W, Buckner J, Bridges L, et al. LB0008 The effect of HLA-DRB1 risk alleles on the clinical efficacy of abatacept and adalimumab in seropositive biologic-naïve patients with early, moderate-tosevere RA: data from a head-to-head single-blinded trial. Ann Rheum Dis. 2019;78:263-4.
32. Curtis JR, Chen L, Bharat A, et al. Linkage of a deidentified United States rheumatoid arthritis registry with administrative data to facilitate comparative effectiveness research. Arthritis Care Res (Hoboken). 2014;66:1790-8. 